\title{
Diversidad en percepciones de la problemática social en el continente americano: cruzando fronteras mediante composiciones musicales
}

\author{
Gilda Pacheco Acuña \\ Escuela de Lenguas Modernas \\ Universidad de Costa Rica
}

\begin{abstract}
Resumen
El siguiente artículo utiliza canciones de diferentes regiones de América escritas al final de la década de los años ochentas por cantautores representativos de Argentina, Costa Rica y Estados Unidos. Estos textos, productos de cultura popular, son analizados como poemas y para dicho estudio se usan tanto estrategias de los enfoques comparativos literarios como premisas de los estudios culturales. Con esta propuesta teórica se busca visualizar interesantes similitudes y señalar importantes diferencias en estas producciones textuales desde diversos contextos históricos, políticos y sociales de los países seleccionados.
\end{abstract}

Palabras claves: literatura comparada, estudios culturales, composiciones musicales como textos literarios, problemática social en América, canciones populares

\begin{abstract}
This article analyzes songs from different regions of the American continent that were written at the end of the decade of the 80 s by representative composers of Argentina, Costa Rica and the United States. These texts, products of popular culture, are analyzed as poems. Therefore, textual strategies from comparative literature as well as premises from cultural studies are used in this study. By means of this theoretical frame, one could visualize interesting similarities and important differences in these texts from diverse historical, political and social contexts of the selected countries.
\end{abstract}

Key words: comparative literature, cultural studies, musical compositions as literary texts, social problems in America, popular songs 
L a problemática social es un tema bastante complejo y extenso que presenta particularidades según la región o la cultura en que esté presente. Además, las percepciones de esta problemática no son uniformes, ya que cada persona tiene una percepción del mundo, de su país, de su sociedad, de su comunidad, de su barrio y cada quien al observar, palpar, confrontar o involucrarse en problemas sociales, tiene algo qué decir, en otras palabras, una reflexión personal que tipifique, justifique o explique su propio contexto social. Sin embargo, a veces el mensaje resulta más directo, influyente y si se quiere "agradable", cuando lo hace un(a) cantautor(a), un(a) compositor(a), quienes a través de sus melodiosas líricas expresan sus críticas y demandas sociales.

Para tales efectos, en este artículo decidí utilizar dos campos académicos, la literatura comparada y los estudios culturales, que al converger facilitan una buena plataforma para lo que pretendo hacer: comparar canciones como textos literarios y cruzar fronteras geográficas utilizando estos mismos textos para ir señalando diferencias y similitudes de los distintos contextos históricos y sociopolíticos de donde emergen.

La literatura comparada manifiesta su carácter interdisciplinario al no considerar exclusivamente el análisis de textos literarios; así como los estudios culturales resultan ser estudios de articulación social que buscan borrar fronteras disciplinarias, geográficas y/o sociales mediante el análisis de productos culturales. El aspecto investigativo de ambas disciplinas ha sido también señalado por los estudios en dichos campos. Mientras que Roland Greene visualiza la literatura compa- rada como "el laboratorio o taller de los estudios literarios" (222, citado en Saussy, traducción propia), Lawrence Grossberg declara que "los Estudios Culturales toman cualquier campo que pueda producir conocimiento necesario para desarrollar un proyecto en particular" (2, traducción propia). Por otro lado, Haun Saussy manifiesta que la literatura comparada es un campo "meta-disciplinario por su condición de apertura a nuevos objetos y formas de investigación" (23). Y esta apertura o expansión mencionada que afirma el crítico, se observa en el campo de los estudios culturales en donde "la cultura es simultáneamente el campo donde se realiza el análisis, el objeto de análisis y el sitio de intervención y crítica política" (Grossberg, 5). En suma, los dos campos citados son extensos e interdisciplinarios. Ambos dan cabida a la investigación y a la crítica social.

En mi opinión, veo la literatura comparada como la predecesora de los estudios culturales, pero algunos críticos han visualizado esta relación de forma diferente y presentan interesantes propuestas. Según Roland Greene, el campo de los estudios culturales es una fuerza renovadora de la literatura comparada (218, citado en Saussy). Para Haun Saussy, la literatura comparada y los estudios culturales se encuentran en competencia (21). Por su parte, Jonathan Culler señala que el aspecto teórico-interdisciplinario es el punto de enlace entre ambos campos (2).

Debido a que el campo de los estudios culturales es bastante amplio, para realizar este estudio he decidido enfocarme en una parte de él, la cultura popular, visualizada como el compendio de ideas, actitudes o productos de la gente, los cuales tipifican a una 
sociedad. Y desde esta perspectiva, analizaré canciones populares, textos idóneos que revelan las preocupaciones y deseos de sus compositores de manera individual pero que a la vez reflejan el contexto social respectivo de su país de origen. Para tales efectos he seleccionado tres canciones de sendos países pertenecientes a las tres divisiones del continente americano: Estados Unidos en América del Norte, Argentina en América del Sur y Costa Rica en América Central. Las tres canciones fueron escritas al final de la década de los 80 , de manera que he trazado coordenadas espaciales y temporales para explorar la visión de la problemática social de estos textos mediante un enfoque de comparación literaria complementado por premisas teórico-culturales. Las canciones seleccionadas son: "Barrio Golondrina" de León Gieco, "Political World" de Bob Dylan y "Barrio" de Juan Carlos Ureña.

\section{Los años ochentas: contextos his- tóricos y políticos en las Américas}

Antes de iniciar el análisis propuesto es prudente revisar el contexto social del país de cada uno de estos compositores durante la década de los ochentas. En Argentina, por ejemplo, tenemos tensión, conflictos e inestabilidad política con cuatro presidentes -Videla, Viola, Galtieri y Bignone- en los primeros años de esa década. En 1983, Raúl Alfonsín asume el poder y en el pueblo argentino se habla entonces de un "regreso a la democracia", pero después de dos años Alfonsín inicia los famosos juicios contra represores militares que crean oposición contra su gobierno y conllevan al final de su período presidencial en 1989. En el campo económico, grandes gastos del gobierno, altos aumentos en salarios, entre otros factores, conducen a la crisis económica del final de la década. La canción de León Gieco, "Barrio Golondrina", es compuesta en 1989 y refleja la preocupación del compositor sobre su sociedad. En este mismo año con su canción "Political World", Bob Dylan nos presentaría un mundo más sombrío que el descrito por Gieco. Pero antes de su análisis, es también prudente mencionar brevemente el contexto histórico-político de los Estados Unidos en dicha década.

En los años ochentas casi un solo presidente está en el poder, el republicano Ronald Reagan quien ocupó la Casa Blanca de 1981 a 1989. El inicio de este periodo es marcado por la "Guerra fría" entre los Estados Unidos y la antigua Unión Soviética, debido a la temida amenaza nuclear. El terrorismo internacional aumenta y se dan revueltas tanto dentro como fuera del país. El mismo presidente Reagan es víctima de un atentado de asesinato y en esa década Estados Unidos ataca Libia e invade Panamá. En cuanto al aspecto económico, Ronald Reagan establece varias medidas de libre comercio que crean la base de la economía neoliberal estadounidense de los siguientes años. Para algunos, estas medidas conducen a crear estabilidad, mientras que para otros contribuyen a una posterior crisis económica. No obstante, la canción "Political World" de Bob Dylan no enfatiza el factor económico, como sí lo hace el compositor costarricense Juan Carlos Ureña en su canción "Barrio". Veamos ahora en forma esquemática el contexto social de Costa Rica en la década propuesta para este estudio. 
La Costa Rica de los años ochentas presenta inestabilidad y tensión al inicio de la década aunque equilibrio al final de esta. Tres presidentes gobernarían en condiciones diferentes. Rodrigo Carazo, quien funda la Universidad para la Paz, finaliza su período en 1982 y enfrenta la difícil recesión económica de los precios del alza del petróleo, mientras que los precios del café, principal producto nacional de aquel tiempo, caían estrepitosamente. Luis Alberto Monge, presidente hasta 1986, desarrolla medidas de austeridad, reduce la inflación y el desempleo e instala una política de neutralidad con la región centroamericana. Finalmente, Oscar Arias, galardonado con el Premio Nobel de la Paz en 1987 por su contribución al tratar de detener la guerra y mejorar las relaciones en los países centroamericanos, termina la década con una economía más estable.

Después de esta pincelada histórica con alusiones de aspectos políticoeconómicos en las tres regiones del continente americano, procedamos al análisis literario de las canciones propuestas como textos que, aunque tradicionalmente no se consideran producciones literarias sino productos de cultura popular, pueden ser estudiados desde esta perspectiva.

\section{Cantautores del continente ameri- cano y sus canciones como textos literarios}

En el siguiente apartado presentaré información sobre los tres cantautores seleccionados y posteriormente se explorarán sus composiciones musicales mediante estrategias literarias tales como: tipos y simbolismo de las imágenes, uso de figuras textuales, selección de pronombres y su efecto en el texto, la estructura y distribución de la versificación en la canción, el análisis del tono, y codificación e impacto de los mensajes de cada cantautor.

Raúl Alberto Antonio Gieco, conocido como León Gieco, nace en Santa Fe, Argentina en 1951. Es un cantautor y compositor de reconocido prestigio tanto en su país natal como internacionalmente. En cuanto a instrumentos musicales, Gieco utiliza la guitarra, el charango y la armónica para acompañar sus líricas. En sus composiciones combina el género folclórico con el rock y crea canciones de protesta para tratar de concientizar a su sociedad. Debido a la presión del gobierno argentino por el contenido de sus letras y la censura impuesta, Gieco abandona su país a finales de los años setentas y reside un tiempo en los Estados Unidos. Pero es en la década de los ochentas cuando su figura se fortalece en el ámbito internacional con giras y conciertos en diferentes lugares como Rusia, Alemania, Austria y en su propio país de origen, Argentina. Su canción "Barrio Golondrina" es parte de su álbum titulado Semillas del corazón que aparece en 1989.

"Barrio golondrina" consta de cinco estrofas compuestas de cuatro líneas cada una. Presenta un tono de denuncia social pesimista ya que no se vislumbra ninguna posibilidad de cambio en la triste situación descrita en este texto. Las imágenes concretas son escasas, pues no se ofrece una descripción propia del lugar o del barrio sino más bien de las actitudes de la gente que lo habita o que indiferente lo observa pues no forma parte de él. Se mencionan "la gente", "una mano", "la 
pena" pero al no describir propiamente el barrio, éste podría ser cualquier lugar, cualquier barrio que presenta condiciones similares ya que en él se contempla la "misma vida que otra villa" (1. 2) como lo dice el cantautor.

Sin embargo, es pertinente señalar que se trata de un lugar marginado en donde "hay promesa y falta todo" (l. 3 ) en donde la gente del lugar "corre atrás del que camina/De ese que camina atrás/de otro que más lejos va" (l. 6-8). En otras palabras, nadie espera a nadie, no hay solidaridad en dicho lugar. El mismo texto lo explica en las líricas del coro: "Porque a casi nadie, nadie le interesa/tirar una mano tan solo por dar/Porque casi nadie sabe qué es más vida/querer regalar un poco de vida" (1. 9-12). Así, la marginalidad de la gente del lugar, su hambre y su pobreza se visualizan en versos que aluden al aspecto económico como "tanto falta que no hay más" (4), o "si hoy la pena tiene suerte/en comida se convertirá" (19-20). Pero tristemente, la marginalidad de los habitantes del Barrio Golondrina no se trata de evitarla o de solucionarla debido a la indiferencia humana "porque la gente olvida" (15). Es interesante señalar que la visión de este microcosmos, carente de recursos e indiferente al dolor humano que nos ofrece Gieco, se torna más sombría e impotente en la canción de Dylan.

Robert Allen Zimmerman, conocido como Bob Dylan, nace en Duluth, Minnesota, en 1941. Cantautor y compositor de renombre internacional, es considerado uno de los músicos más influyentes y prolíficos del siglo XX e inicios del siglo XXI. Entre sus géneros destacan el rock, el folk rock, el country rock, el rock and roll y los blues. Dylan toca la guitarra, la armónica y el piano.
Sus líricas, a veces acompañadas de imágenes surrealistas, presentan una variedad de temas sociales, políticos y filosóficos que conllevan a la protesta social. Dylan es también considerado un reconocido poeta americano y en varias ocasiones su nombre ha figurado en la lista de candidatos al Premio Nobel de Literatura. Aunque su carrera como músico ha tenido épocas controversiales y recepciones negativas de algunas de sus producciones, al final de los años 80, su carrera resurge con el lanzamiento de su álbum Oh Mercy del cual la canción "Political World" forma parte.

"Political World" consta de cincuenta y cinco versos agrupados en diez estrofas. Con el uso del pronombre "we" (nosotros) y la frase repetitiva "We live in a political world" (Vivimos en un mundo político), la canción apela directamente a las personas que pueblan ese mundo descrito en el texto. El adjetivo "político" es sinónimo de negatividad, pues el mundo que presenta Dylan es un lugar carente de valores, lleno de vicios y corrupción. Se trata de un mundo donde "Love don't have any place" (1. 2, el amor no tiene un lugar) y en el cual "Wisdom is thrown in jail" (l. 11, a la sabiduría se le encierra en prisión), donde "Mercy walks the plank" (l. 17, la misericordia camina por la plancha), donde "peace is not welcome at all" (1. 47, la paz no es bien recibida) $y$ "Courage is a thing of the past" (1. 22, el coraje es cosa del pasado).

Las imágenes de sus letras corresponden no a una descripción del lugar física o geográficamente hablando, sino más bien presentan una descripción de sus habitantes, seres que ensucian y contaminan desde que se levantan, que no quieren niños, que 
cometen crímenes y que viven en ciudades de miedo y en "houses [that] are haunted" (1. 23, casas que están embrujadas). El poder o control hegemónico corrompe el lugar y la gente no trata de evitarlo. La vida es solo apariencia, pues "Life is in mirrors" (1. 18, la vida se refleja en los espejos) y lo importante es poseer, ya que "Everything is hers and his" (1. 52, todo es de ella o de él). Sin embargo, los seres que pueblan el mundo de Dylan contrastan con los habitantes del barrio de Ureña quienes son descritos como potenciales agentes de cambio.

Juan Carlos Ureña nace en San José, Costa Rica, en 1960. Cantautor y compositor, quien representó a nuestro país en diversos conciertos internacionales en Rusia, España, Cuba, Tahití, Holanda y Argentina, fue el fundador y guitarrista del grupo Oveja negra en los años noventas. Junto con Rubén Pagura, Ureña escribe y produce varias piezas musicales que enfatizan el tema de identidad cultural y nacional como "El Cristo de las Indias", "La Cantata Centroamericana" y "La Patria Grande", entre otras. Su género musical es lo que se conoce como "nueva trova" o canción de autor. Actualmente, Ureña es profesor en Texas en Stephen Austin State University. Cuenta con un doctorado en estudios hispánicos y una maestría en composición musical. Sus intereses musicales y culturales los canaliza en diversas publicaciones sobre canción popular y folclor, canción medieval europea y poesía hispanoamericana. Su publicación más reciente es el libro titulado Trovar. Memoria poética de la canción centroamericana (2013).

La canción "Barrio" de Juan Carlos Ureña fue grabada en 1989. El texto consta de cincuenta y dos líneas di- vididas en seis estrofas. A diferencia de la apelación directa al barrio que hace Gieco o del uso del "nosotros" que hace Dylan, en la canción de Ureña el "yo" lírico es quien abre la ventana y contempla su barrio. La problemática social de la pobreza se vislumbra desde el principio del texto. Al concluir la primera estrofa, se nos dice que al querer lavarse la cara, "el agua ya se fue y solo queda pa'l café" (1. 6). Al describir el lugar, pues de las tres canciones esta es la única que nos ofrece imágenes concretas, se habla "de los techos herrumbrados/ya los gatos se han marchado" (1. 9-10). En la tercera estrofa, Ureña aclara que se trata de un barrio del sur, zona marginada de San José de Costa Rica, en donde "los hombres del mañana/habitan su dolor" (1.20-21).

Las personificaciones forman también parte de las figuras literarias de esta canción, puesto que "la mañana está tocando a la puerta" (1. 8) y "anda la esperanza por la acera” (1. 25). El texto demanda una acción en conjunto para tratar de ayudar a esta zona ya que la canción dice: "Barrio hoy es tiempo de abrazarnos/ y ensancharnos los caminos/de cuidar a cada niño/tiempo de salvar tus ríos del veneno y del olvido" (1. 30-35). Aunque vemos que se hace alusión no solo a pobreza, sino también al abandono infantil y a la contaminación ambiental, de las tres canciones, la de Ureña es la que presenta un tono más positivo, pues aunque la esperanza "en el caño se ha caído/un chiquillo la levanta" (1. 25-26), "le acaricia con ternura/y las ganas de vivir [a la esperanza] le vuelven a sonreír" (1. 28-29). Y no solo los niños sino los adultos del barrio que habitan su dolor caminan “... a construir la primavera y a salvarnos 
el porvenir" (1. 22-23). Estas últimas líneas recurrentes en el texto afirman el optimismo del cantautor.

\section{Composiciones musicales como manifestaciones culturales}

$\mathrm{Al}$ considerar algunas premisas del enfoque de los estudios culturales, vemos cómo las canciones también son productos culturales. Resulta válido entonces cuestionarnos lo siguiente: ¿Cómo nacen las canciones populares? ¿Cómo las recibe el público? ¿Qué efectos crean éstas en la sociedad? Las tres canciones seleccionadas nacen de la preocupación del cantautor respectivo sobre los problemas que aquejan su contexto social. Cada "fan" las interpretará según su edad, experiencia de vida y su propio contexto, pues como Wendy Griswold lo afirma, los receptores interpretan los objetos culturales para producir sus propios significados (83), aunque en este caso los cantautores esperarían que se rescate el mensaje social para que se reflexione sobre su sentido. Así, los procesos políticos, sociales y económicos forman culturas y sociedades ya que "cada cultura genera sus propios significados mediante sus estructuras sociales, instituciones, creencias y prácticas" (Meyers 109, traducción propia).

Sin embargo, no debemos olvidar que las canciones son productos culturales masivos, producidas, como Dominic Strinati lo dice, "por técnicas de producción industrial para lograr ganancias y van dirigidas al público, visualizado como consumidores en masa" (10, traducción propia). Por lo tanto, como lo dijo Jonathan Culler, "la cultura popular se hace de la cultu- ra en masa" (244, traducción propia). Además, los músicos aumentan su popularidad si cuentan con una mejor difusión para lograr una mayor recepción. Si bien es cierto que pertenecen a mercados culturales que corresponden a cambios sociales (Griswold, 80), la recepción de las canciones a veces no se puede prever.

Es importante destacar que, como lo señala Simon Frith, hacer música es "una expresión y celebración de sociabilidad" (citado en Grossberg, 177). Sin embargo, en el caso de estas tres canciones más que celebración vemos una denuncia social fuerte, aunque percibida de forma diferente. Son entonces problemáticas sociales que cruzan fronteras, pues como lo dice Katie Trumpener, el trabajo de la musicología práctica ha desarrollado los nuevos paradigmas de la influencia entre culturas (187, citada en Saussy, traducción propia). Así, las canciones no solo son compuestas, cantadas y recordadas por su musicalidad sino también sirven para transmitir importantes mensajes a la sociedad y mostrar que hay problemas difíciles de solventar que acontecen en diferentes lugares por igual.

\section{Consideraciones finales}

Al considerar los métodos comparativos literarios, vemos cómo, además del concepto de intertextualidad usado como eje clave en las comparaciones, la búsqueda de influencias ha sido casi una obsesión en la literatura comparada. La pregunta entonces sería: ¿existe alguna influencia en estos tres cantautores y quién influenció a quién? En orden cronológico según sus fechas de nacimiento, una década separa a cada 
cantautor. Por su temática social y la utilización del género folk rock, a León Gieco, quien vivió en los Estados Unidos, se le ha llamado "el Dylan de Argentina". Gieco a la vez fue una gran influencia para los músicos de Centroamérica. El mismo Ureña lo comenta y lo dice: "Sobre León Gieco, lo conocí personalmente en Moscú en 1985 y luego lo vi de nuevo en Nicaragua. Me encanta su música y de hecho me influyó mucho. También tuve la influencia de Bob Dylan, los Beatles y otros artistas angloparlantes, pero como en aquel entonces yo no sabía inglés la influencia que recibí de ellos fue sobre todo musical" (correo electrónico, 7 de diciembre de 2014).

Si recorremos los acontecimientos de los años ochentas, vemos cómo en Argentina el final de dicha década es también el final de la presidencia de Raúl Alfonsín, cuyo gobierno de opresión provocó el desengaño y frustración del pueblo argentino, quien también enfrentó una crisis económica al final de los años ochentas. Por eso la frase en la canción de Gieco "hay promesa y falta todo" se sustenta desde el nivel político y económico. En los Estados Unidos no hay una fuerte preocupación económica sino más tensión por la amenaza de una guerra nuclear, una lucha de poderes entre dos potencias la cual crea un mundo político sin valores y sin sueños ya que, como lo dice Dylan, "The next day could be your last” (1. 25, el próximo día puede ser el último). Mientras que en Costa Rica al final de la década se adquiere estabilidad en comparación con su inicio de alta presión económica, y este tiempo mejor se refleja en Ureña cuando afirma que los hombres del barrio caminan “. . a construir la primavera" (1. 22).
Y así, hemos hecho un breve recorrido musical por el continente americano, enmarcado al final de la década de los años ochentas. Bob Dylan describe un mundo bastante sombrío, señala sus vicios pero no cuestiona su origen ni ofrece soluciones de cambio. León Gieco presenta una zona marginal, víctima de la indiferencia social, que podría encontrarse en cualquier lugar. Juan Carlos Ureña habla de un barrio del sur, señala sus problemas sociales, pero ve esperanza si se toma consciencia y se actúa para mejorar la situación. ¿Pesimismo, reflexión, idealismo? Lo cierto es que estos tres cantautores perciben un mundo de diversos problemas que no nos es indiferente, pues como lo canta Dylan "We live in a political world/The one we can see and feel" (Vivimos en un mundo político que podemos ver y sentir) en donde, como dice Gieco, “. . . casi nadie sabe qué es más vida, querer regalar un poco de vida" y por lo tanto, según Ureña "como la historia nos reclama/es hora de salir" a construir un mejor porvenir.

\section{Bibliografía}

Behdad, Ali y Dominic Thomas, eds. A Companion to Comparative Literature. Massachusetts: Wiley-Blackwell, 2011. Impreso.

Bernheimer, Charles, ed. Comparative Literature in the Age of Muticulturalism. Baltimore: The Johns Hopkins University Press, 1995. Impreso.

Bianciotto, Jordi. Guía Universal del Rock: de 1970a 1990. Barcelona: Ediciones Robinbook, 2009. Impreso.

Culler, Jonathan. The Literary in Theory. Standford: Standford University Press, 2007. Impreso. 
Gamboa Goldenberg, Jaime, Carlos Vargas Unfried y Carlos Castro Cantillo. La música de nuestra nación. San José: Grupo Nación, 2012. Impreso.

Griswold, Wendy. Cultures and Societies in a Changing World. Los Angeles: Sage Publications, Inc. 2013. Impreso.

Grossberg, Lawrence, Cary Nelson y Paula Treicher, eds. Cultural Studies. New York: Routledge, 1992. Impreso.

López Rodríguez, Javier María. Breve historia de la música. Madrid: Ediciones Nowtilus, S.L., 2011. Impreso.

Meyers, Kari y Gilda Pacheco. The Perceptive Process: An Introductory Guide to Literary Criticism. San José: Editorial Universidad de Costa Rica, 2012. Impreso.

Saussy, Haun, ed. Comparative Literature in an Age of Globalization. Baltimore: The Johns Hopkins University Press, 2006. Impreso.

Strinati, Dominic. An Introduction to Theories of Popular Culture. New York: Routledge, 1995. Impreso.

Tötösy de Zepetnek y Tutun Mukherjee, eds. Companion to Comparative Literature, World Literatures, and Comparative Cultural Studies. New Delhi: Cambridge University Press India, Ptv. Ltd. 2013. Impreso.

Tyson, Lois. Critical Theory Today. New York: Routledge, 2006. Impreso.

Ureña, Juan Carlos. Trovar. Memoria poética de la canción hispanoamericana. San José: Editorial Universidad de Costa Rica, 2013. Impreso.

\section{Fuentes en línea:}

Ureña, Juan Carlos. Correos electrónicos (noviembre, diciembre 2014)
http://es.wikipedia.org/wiki/Bob_ Dylan

http://es.wikipedia.org/wiki/León_Gieco htpp://www.89decibeles.com/noticias/ juan-carlos-ureña-presentatrova...

htpp://www.mondolatino.eu/ocio/ artistas/juancarlosurena.php

\section{Barrio Golondrina (León Gieco, 1989)}

Barrio golondrina misma vida que otra villa Hay promesa y falta todo, tanto falta que no hay más.

Barrio golondrina corre atrás del que camina. De ese que camina atrás de otro que más lejos va.

Porque a casi nadie, nadie le interesa tirar una mano tan solo por dar.

Porque casi nadie sabe qué es más vida, querer regalar un poco de vida.

Barrio golondrina corre a un costado del día. Porque la gente se olvida, más de dos pasos que da.

Barrio golondrina resto que se desperdicia si hoy la pena tiene suerte en comida se convertirá.

\section{Political World \\ (Bob Dylan, 1989)}

We live in a political world Love don't have any place We're living in times 
Where men commit crimes

And crime don't have any face.

We live in a political world

Icicles hanging down

Wedding bells ring

And angels sing

Clouds cover up the ground.

We live in a political world

Wisdom is thrown in jail

It rots in a cell

Is misguided as hell

Leaving no one to pick up a trail.

We live in a political world

Where mercy walks the plank

Life is in mirrors

Death disappears

Up the steps into the nearest bank.

We live in a political world

Where courage is a thing of the past

Houses are haunted

Children unwanted

The next day could be your last.

We live in a political world

The one we can see and feel

But there's no one to check

It's all a stacked deck

We all know for sure that it's real.

We live in a political world

In the cities of lonesome fear

Little by little

You turn in the middle

But you're never sure why you're here.

We live in a political world

Under the microscope

You can travel anywhere

And hang yourself there

You always got more than enough rope.

We live in a political world

Turning and trashing about

As soon as you're awake
You're trained to take

What looks like the easy way out.

We live in a political world

Where peace is not welcome at all

It's turned away from the door

To wonder some more

Or put up against the wall.

We live in a political world

Everything is hers and his

Climb into the frame

And shout God's name

But you're never sure what it is.

\section{Barrio \\ (Juan Carlos Ureña, 1989)}

Abro la ventana, amanece

se levanta una montaña

en la calle descubierta

se querrá lavar la cara

pero el agua ya se fue y solo queda pa'l café.

Abro la ventana, la mañana está tocando la puerta de los techos herrumbrados ya los gatos se han marchado es domingo, buena suerte la mejenga ha comenzado nadie gana nadie pierde.

Barrio, barrio del sur en ti cabalga el tiempo

la infancia que viví

la historia nos reclama

es hora de salir

oh barrio, barrio del sur

los hombres del mañana

habitan tu dolor

caminan sin escuela a construir la pri-

mavera

y a salvarnos el porvenir.

Anda la esperanza por la acera 
En el caño se ha caído Un chiquillo la levanta $\mathrm{y}$ en sus manos se hace nido la acaricia la ternura y las ganas de vivir le vuelven a sonreír.

Barrio hoy es tiempo de abrazarnos y ensancharnos los caminos de cuidar a cada niño tiempo de salvar tus ríos del veneno y del olvido cada casa, cada madre se merece otro destino oh, oh, oh.
Barrio, barrio del sur en ti cabalga el tiempo la infancia que viví la historia nos reclama es hora de salir oh barrio, barrio del sur los hombres del mañana habitan tu dolor caminan sin escuela a construir la primavera

y a salvarnos del barrio...barrio del sur los hombres del mañana habitan tu dolor caminan sin escuela a construir la primavera

y a salvarnos el porvenir. 
